\title{
EPIDEMIOLOGY OF GASTRIC TREMATODES IN NILE TILAPIA, ASSIUT GOVERNORATE
}

\section{A.A. ELKAMEL}

Fish Diseases and Management, Department of Animal Medicine, Faculty of Veterinary Medicine, Assiut University

\begin{tabular}{ll} 
ABSTRACT \\
\hline \\
The aim of this study was to investigate the prevalence of infestation and \\
seasonal and age susceptibility of Nile tilapia, Oreochromis niloticus to \\
Enterogyrus cichlidarum over a calendar year. Two weight groups of 100- \\
$150 \mathrm{~g}$ and $150-200 \mathrm{~g}$ were investigated over the four seasons. Results showed \\
that the average prevalence of E. cichlidarum over a calendar year was \\
20.56\% for the lighter-weight (younger) group, but was $26.11 \%$ for the \\
second (older) group. The highest prevalence was during the spring season. \\
The older fish showed higher prevalence and intensity of infestations all over \\
the four seasons. Surprisingly, the fish gastric submucosa showed encysted \\
metacercaria of digenean trematodes (13.61\%). The highest prevalence was \\
during the winter season with the average prevalence all over the year of \\
$11.67 \%$ and $15.56 \%$ for the younger and older groups, respectively. \\
Histopathological studies revealed mild alteration at the site of attachment of \\
E. cichlidarum to the gastric mucosa and a local chronic inflammatory \\
reaction around the encysted digenea within the submucosa.
\end{tabular}

Keywords: Nile tilapia, Enterogyrus cichlidarum, Digenea, Gastric trematodes

\section{INTRODUCTION}

Monogenean trematodes are commonly found on the surface and gills of freshwater and marine fishes (Bakke et al., 2002; Thatcher, 2006). Amongst the Dactylogyridea, some show unusual localization, as oesophagus, urinary bladder and ureters (Pariselle A. and Euzet L., 2009), or in the stomach and viscera of cichlid fish (Noga and Flowers, 1995). Genus Enterogyrus currently includes seven species, which are all parasites of the stomach in fishes of the family Cichlidae (Pariselle A. and Euzet L., 2009). Enterogyrus cichlidarum Paperna, 1963, a parasite of Tilapia zillii Gervais, 1848 and Nile tilapia, Oreochromis niloticus (L.) Occasionally, E. cichlidarum causes chronic mortalities in tilapia as was reported by Noga and Flowers (1995). In addition, it leads to gastrointestinal abrasions which facilitate the invasion of the opportunistic microorganisms (Kabata, 1985). Parasitic infestation might act as a stress factor inducing a decrease in the body weight, lower the resistance, and thus rendering the fish more susceptible to diseases (Hoffma et al., 1990).

The aim of this study is to investigate the prevalence and intensity of infestations of Nile tilapia with E. cichlidarum over one year. In addition, clinical and postmortem findings and histopathological alterations of infested fish stomachs were studied.

\section{MATERIALS and METHODS}

\section{Fish collection:}

Three hundreds and sixty alive Nile tilapia, Oreochromis niloticus, were collected over a calendar year from El-Ibrahemia canal and its tributaries, Assiut city. To investigate the weight susceptibility of Nile tilapia to E. cichlidarum, collected fish were divided according to the body weight into two groups with180 fish each. Fish of the first group weighed $100-150 \mathrm{~g}$ each, while fish of the second group weighed 150-200g each. Fish were collected over the four seasons with 15 fish of each weight group were collected and examined each month to investigate the seasonal susceptibility to E. cichlidarum.

\section{Clinical and parasitological examination of fish:}

Fish were clinically examined after capture for any apparent clinical signs or lesions. Fish were dissected according to Noga (2010) to reach the digestive tract. The stomach was removed by two incisions, one at the end of oesophagus and the other one after the pyloric sphincter. Stomachs were longitudinally incised and coarse particles were gently removed. Incised stomachs were washed by normal saline, 
immersed in 5\% neutral buffered formalin for $10 \mathrm{~min}$ and microscopically examined for the presence of the monogenean, E. cichlidarum that was identified according to Yamaguti (1985).

According to Bush et al. (1997), prevalence rates of infestation were calculated as the number of fish infested divided by the number of fish examined for a parasite species, while the mean intensity of infestations were calculated as the total number of a parasite species divided by the number of fish infested with that parasite.

\section{Histopathological examination}

Infested stomachs were fixed in $10 \%$ neutral buffered formalin for 48 hours, gradually dehydrated, embedded in paraffin. Thin paraffin sections were stained with Haematoxylin and Eosin $(\mathrm{H} \& \mathrm{E})$ to be microscopically examined.

\section{RESULTS}

Clinical and post mortem examination of collected fish revealed mild clinical signs of E. cichlidarum. Fish showed signs of emaciation with enlarged head (18\%). Fish gastric mucosa had a moderate inflammatory response to worms present in the stomach $(11.67 \%)$. The internal organs of heavily infested fish $(8.89 \%)$ were pale and aneamic.
Microscopic examination of Nile tilapia stomachs showed the monogenean E. cichlidarum attached to the gastric mucosa (Fig 1A and 1B). The prevalence of infestation with E. cichlidarum was $23.33 \%$ $(\mathrm{n}=360)$ among all collected fish. Interestingly, the fish gastric submucosa showed encysted digenean metacercaria (Fig 2A and 2B). The prevalence of encysted digenean trematode in examined fish $(n=360)$ was $13.61 \%$. Seasonal and weight susceptibility of Nile tilapia to E. cichlidarum or digenean trematode infestations are summarized in Table 1 and 2, respectively. Intensities of infestation with E. cichlidarum or digenean trematodes over the four seasons for both weight groups are summarized in Table 1 and 2, respectively. There were mixed infestations of the fish with both E. cichlidarum and digenean trematodes (Table 3 and Fig 3).

Histopathological examination results showed that enterogyrus worms have incited a mononuclear inflammatory response. Focal to diffuse inflammations consist of various mixtures of macrophages and lymphocytes that were limited to the sites of attachment of the parasites. Digenea cysts incited necrosis of the gastric glands (Fig 4) with severe inflammation and cellular reactions observed underneath the damaged gastric glands in the submucosa (Fig 2B).

Table 1: Prevalence and mean intensity of Enterogyrus cichlidarum attached to the gastric mucosa of Nile tilapia, Oreochromis niloticus, over the four season. ( $\mathrm{n}=180$ for each weight group).

\begin{tabular}{|c|c|c|c|c|c|c|}
\hline & & Winter & Spring & Summer & Autumn & Avg \\
\hline \multirow{2}{*}{$\begin{array}{l}1^{\text {st }} \text { weight } \\
\text { group (100- } \\
150 \mathrm{~g})\end{array}$} & Prevalence & $22.22 \%$ & $31.11 \%$ & $20.00 \%$ & $8.89 \%$ & $20.56 \%$ \\
\hline & $\begin{array}{l}\text { Mean } \\
\text { intensity }\end{array}$ & 4.70 & 5.86 & 3.56 & 2.5 & 4.62 \\
\hline \multirow{2}{*}{$\begin{array}{l}2^{\text {nd }} \text { weight } \\
\text { group (150- } \\
200 \mathrm{~g})\end{array}$} & Prevalence & $26.67 \%$ & $37.78 \%$ & $28.89 \%$ & $11.11 \%$ & $26.11 \%$ \\
\hline & $\begin{array}{l}\text { Mean } \\
\text { intensity }\end{array}$ & 5.17 & 6.23 & 3.85 & 2.6 & 4.91 \\
\hline
\end{tabular}

Table 2: Prevalence and mean intensity of encysted metacercaria of digenean in the gastric submucosa of Nile tilapia, Oreochromis niloticus, over the four season. ( $\mathrm{n}=180$ for each weight group).

\begin{tabular}{lcccccc}
\hline & & Winter & Spring & Summer & Autumn & Avg \\
\hline \begin{tabular}{l}
$1^{\text {st }} \begin{array}{l}\text { weight group } \\
(100-150 \mathrm{~g})\end{array}$ \\
\cline { 2 - 7 }
\end{tabular} & Prevalence & $20.00 \%$ & $13.33 \%$ & $4.44 \%$ & $8.89 \%$ & $11.67 \%$ \\
\hline \begin{tabular}{l}
$2^{\text {nd }} \begin{array}{l}\text { weight group } \\
(150-200 \mathrm{~g})\end{array}$ \\
\cline { 2 - 7 }
\end{tabular} & Prevalence & $24.44 \%$ & $15.56 \%$ & $8.89 \%$ & $13.33 \%$ & $15.56 \%$ \\
\cline { 2 - 7 } & Mean intensity & 4.82 & 3.71 & 2.75 & 3.33 & 3.93 \\
\hline
\end{tabular}


Table 3: Prevalence of mixed infestation of Nile tilapia, Oreochromis niloticus with Enterogyrus cichlidarum and encysted digenean metacercaria. ( $n=180$ for each weight group)

\begin{tabular}{lccccc}
\hline & Winter & Spring & Summer & Autumn & Avg \\
\hline $\begin{array}{l}1^{\text {st }} \text { weight group } \\
(100-150 \mathrm{~g})\end{array}$ & $8.89 \%$ & $13.33 \%$ & $4.44 \%$ & $2.22 \%$ & $7.22 \%$ \\
\hline $\begin{array}{l}2^{\text {nd }} \text { weight group } \\
(150-200 \mathrm{~g})\end{array}$ & $13.33 \%$ & $20 \%$ & $8.89 \%$ & $4.44 \%$ & 11.67 \\
\hline
\end{tabular}
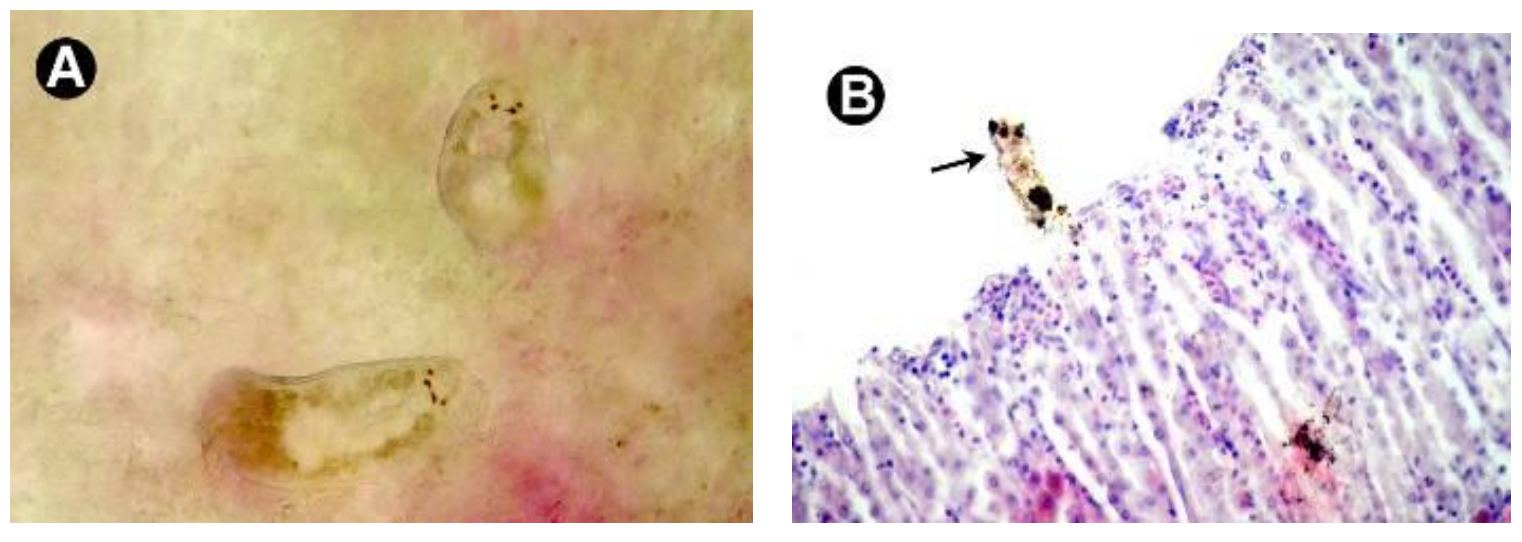

Fig.1: Enterogyrus cichlidarum attached to the gastric mucosa of Nile tilapia, Oreochromis niloticus, (A) a wet mount, $X=400$. (B) H\&E, $X=200$
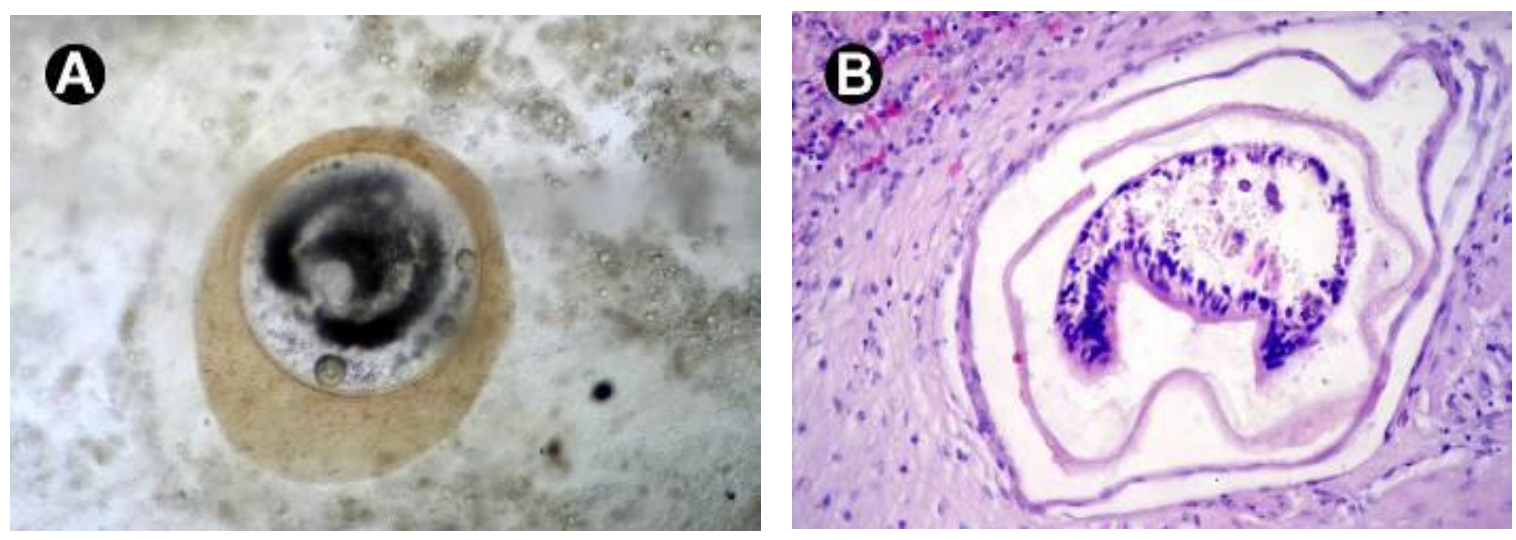

Fig. 2: Encysted digenean metacercaria at the gastric submucosa of Nile tilapia, Oreochromis niloticus, (A) a wet mount, $X=400$. (B) local reaction around the cyst in the gastric submucosa $H \& E,, X=400$ 


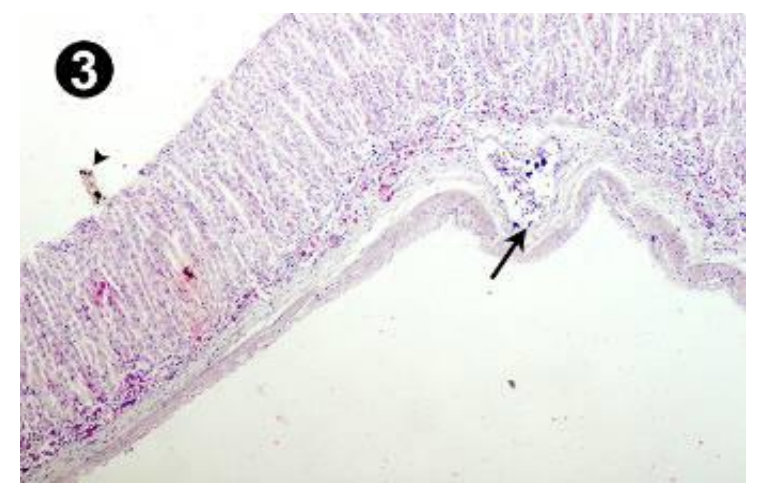

Fig. 3: Nile tilapia, Oreochromis niloticus stomach showing Enterogyrus cichlidarum (arrow head) attached to the gastric mucosa, and encysted digenean metacercaria at the early stage of encystation (not all layers are formed) in the gastric submucosa , H\&E, $\mathrm{X}=100$

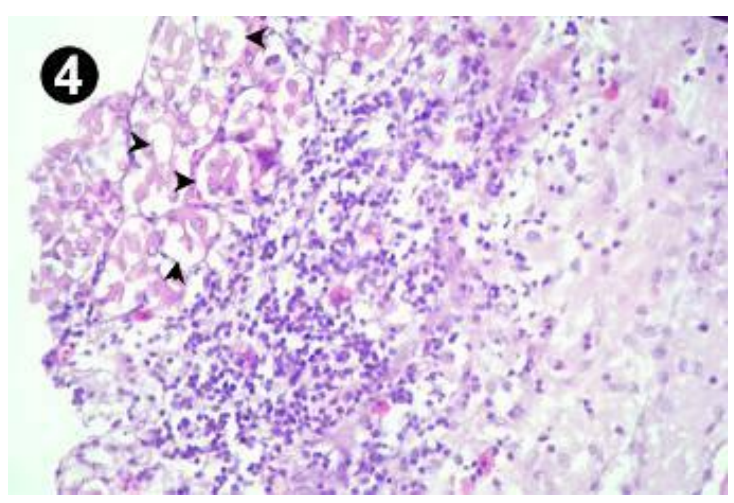

Fig. 4: Nile tilapia, Oreochromis niloticus stomach showing necrosis of the gastric glands (arrow heads) caused by encysted digenean metacercaria $H \& E, X=400$.

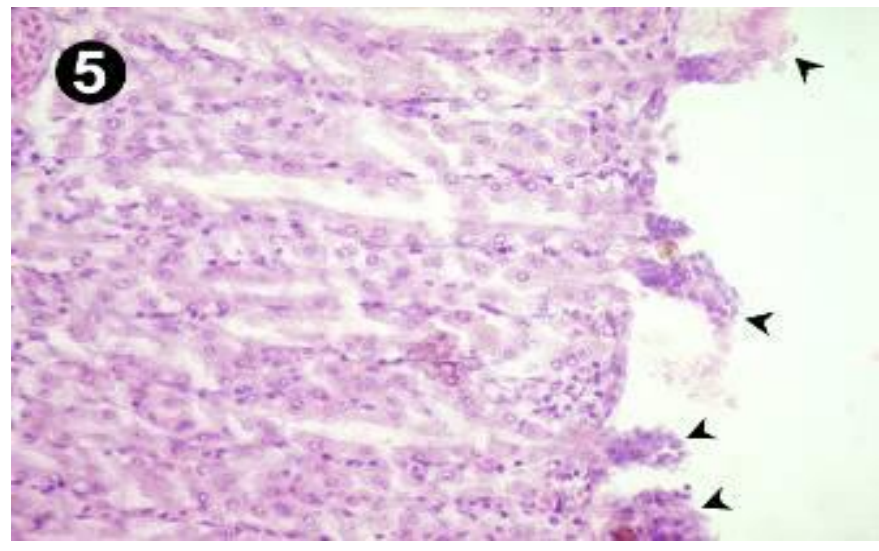

Fig. 5: Nile tilapia, Oreochromis niloticus stomach showing several Enterogyrus cichlidarum worms (arrow heads) attached to the gastric mucosa, $\mathrm{H} \& \mathrm{E}, \mathrm{X}=200$

\section{DISCUSSION}

The aim of this study was to investigate the prevalence and age and seasonal susceptibility of Nile tilapia to Enterogyrus cichlidarum in Upper Egypt. Results show that $23.33 \%$ of all examined fish of the two weight groups were infested with E. cichlidarum. Interestingly, $13.61 \%$ of examined fish were infested with encysted digenean metacercaria. The study was conducted over a calendar year and results showed that stomachs of Nile tilapia examined were infested with a diverse population of monogenean and digenean trematodes.

Results of age susceptibility of Nile tilapia to E. cichlidarum showed that prevalence and intensity of infestations are higher in larger and presumably older Nile tilapia $(150-200 \mathrm{~g})$ than in smaller and presumably younger ones $(100-150 \mathrm{~g})$. These results are comparable to those of Gonzalez-Lanza and
Alvarez-Pellitero (1982) on Dactylogyrus legionensis from Barbus barbus bocagei and of Cone and Burt (1985) on Urocleidus adspectus from Perca flavescens. A possible explanation for the present observations is that the fish accumulate more parasites as the host gets older, although, the lifespan of the adult parasites is not known. On the other hand, there was a sharp fall of parasite numbers in summer and autumn that may indicate that the parasites may only live for a single year. Alternatively, larger hosts may have greater body surface areas providing larger targets for invading oncomiracidia, as has been previously suggested by Cone and Burt (1985) to explain a similar phenomenon with the monogenean U. adspectus.

Similar observations have been recorded for the digenean cyst infestations of Nile tilapia. Larger and older fish had more parasites per infested fish (intensity of infection) and higher prevalence of infestations than had the younger fish. Such findings 
may be due to the feeding behavior of older fish that could be more aggressive and diverse. Comparable results were reported by Paperna (1980) and Aloo (2002) who stated that the prevalence rate of infestation with Clinostomum species was higher in larger fish than in the younger ones.

Investigating the seasonal susceptibility of Nile tilapia to E. cichlidarum showed that the highest levels of prevalence and intensity of infestations occur in the spring. Infection levels were surprisingly high in winter, as the temperature is considered to be the most important factor affecting the seasonal variations of monogenea (Chubb, 1977). These observations combined with the decline in the levels of parasites in the hot months of summer and early autumn suggest that the optimum temperature for reproduction and development of E. cichlidarum may lie at the lower end of the annual temperature range. Perhaps reproduction and development of the parasite slow down or cease during the hot weather beginning near the end of the spring season (khidr, 1990).

The abundance of monogenea during the winter has been reported from other regions of the world as in the USA (Rawson and Rogers, 1972), and in Spain (Gonzalez-Lanza and Alvarez-Pellitero, 1982). The abundance of parasites at relatively low temperatures may occur because such temperatures are below the level at which antibodies are produced by the host but above the minimum temperature required for parasite reproduction (Rawson and Rogers, 1972 and Cloutman, 1978).

Unlike the monogenea, the prevalence of digenean cysts in Nile tilapia is highest during the winter season. Results of the current study showed that the average prevalence of infestation in Nile tilapia over a calendar year was $13.61 \%$. Other studies, reported that the prevalence rate of yellow grub in tilapia species were 25\% (El- Banna, 1999) and 30\% (Eissa et al., 2000).

The prevalence of digenean infestation may be attributed to the availability of snails, environmental temperature and frequency of attack of piscivorous birds (Eissa, 2004). The higher incidence during the winter months may be due to the higher infectivity of the parasite or the abundance of the snails during the pre-winter months (Shareef and Abidi, 2012). The lowest prevalence of digenean infestation in the summer and autumn may be due to flooding of the River Nile. The chances of infestation are less in a larger volume of water, or alternatively, the infective stage larvae may be washed away by the fast stream of water during those seasons (Shareef and Abidi, 2012).

Histopatholgical studies showed that both the monogenea and digenea have induced mild changes in the stomachs of Nile tilapia. E. cichlidarum caused mild damages at site of the attachment probably by the hooks used for attachment of the parasite to the mucosa of the stomach. The use of hooks by E. cichlidarum for attachment compromises the integrity of the gastric mucosa that may create a port of entry for other pathogens (Noga and Flowers 1995; Eissa et al., 2011).

Local reactions were observed around the encysted digenean metacercaria in the submucosa of Nile tilapia stomachs. It is important to note that this may be unusual site for metacercaria encystation. Alternatively, it could be a non-specific target tissue for digenean encystation. There were no indications that these metacercaria were migrating to somewhere else or another target organ, as they were fully encysted with local reaction around them.

In conclusion, this study proved that the gastric trematodes incite moderate clinical signs and lesions in Nile tilapia that may negatively affect the body condition and general health of fish and may lower the fish resistance to other infectious diseases. Infestations were highest during the spring and winter season with the older fish were more susceptible to infestation than the younger ones.

\section{ACKNOWLEDGMENT}

I would like to thank Prof. Dr. Salah H. Afifi, professor of fish pathology for his generous help in the histopathological studies of this work.

\section{REFERENCES}

Aloo, P.A. (2002): A comparative study of helminth parasites from the fish Tilapia zillii and Oreochromis leucostictus in Lake Naivasha and Oloidien Bay, Kenya. J. Helminthol., 76: 95- 102.

Bakke, T.A.; Harris, P.D. and Cable, J. (2002): Host specificity dynamics: observations on gyrodactylid monogeneans. International Journal of Parasitology, vol. 32, pp. 281-308.

Bush, AO.; Lafferty, KD.; Lotz, JM. and Shostak, AW. (1997): Parasitology meets ecology on its own terms: Margolis et al. revisited. J Parasitol. 1997 Aug; 83(4): 575-83

Chubb, JC. (1977): Seasonal occurrence of helminths in freshwater fishes. Part I. Monogenea. Advances in Parasitology 15: 133-199.

Cloutmand, D.G. (1978): Abundance of Cleidodiscus pricei Mueller (Monogenea: Dactylogyridae) on the flat bullhead, Ictalurus platycephalus (Girard) in Lake Norman, North Carolina. Journal of Parasitology 64: 170-172.

Cone, D.K. and Burt, M.D. (1985): The population biology of Urocleidus adspectus Mueller, 1936 (Monogenea) on Perca flavescens in New Brunswick. Canadian Journal of Zoology 63: 272-277. 
Eissa, IAM. (2004): Parasitic fish diseases in Egypt. Dar El-Nahdda, El-Arabia Publishing, Cairo, Egypt

Eissa, IAM.; Badran, AF.; Diab, AS. and Laya, F. (2000): Studies on yellow grub disease in some freshwater fishes. Scientific Conference, Suez Canal Univ. Med. J. 3 (2) 401-410.

Eissa, IAM.; Gado, MS.; laila, AM.; Mona S. Zaki and Noor El-Deen, A.E (2011): Field studies on Prevailing Internal Parasitic Diseases in Male and hybrid tilapia relation to Monosex Tilapia at Kafr El-Sheikh Governorate Fish Farms. Journal of American Science,7 (3).

El-Banna, LF. (1999): Studies on yellow grub disease in some freshwater fishes. PhD Thesis, Faculty of Veterinary Medicine, Suez Canal University.

Gonzalez-Lanza, M.A. and Alvarez-Pellitero, OM. (1982): Description and population dynamics of Dactylogyrus legionensis n. sp. from Barbus barbus bocagei Steind. Journal of Helminthology 56: 263-273.

Hoffmann, RW.; Körting, W.; Fischer-Scherl, T. and Schäfer, W. (1990): An outbreak of bucephalosis in fish of the Main river. Angew Parasitol. 1990 May; 31(2): 95-9.

Kabata, Z. (1985): Parasites and diseases of fish culture in the tropics. Printed in Great Britain by Taylor and Franks (Ltd. Basingstoke Hants). Pp 127-161.

Khidr, A.A. (1990): Population dynamics of Enterogyrus cichlidarum (Monogenea: Ancyrocephalinae) from the stomach of Tilapia spp. in Egypt. International Journal for Parasitology 20: 741-747.
Noga, E.J. (2010): Fish disease Diagnosis and Treatment. Mosby-yearbook, Inc. Watsworth Publishing Co., USA.

Noga, JI. and Flowers, JR. (1995): Invasion of Tilapia mossambica (Cichlidae) viscera by the monogenean Enterogyrus cichlidarum. Journal of Parasitology, vol. 81, pp. 815-817.

Paperna, I. (1980): Parasites, infections and diseases of fish in Africa. In: FAO - CIFA Tech. Pap 7. Roma. pp. 79-85.

Pariselle, A. and Euzet, L. (2009): Systematic revision of dactylogyridean parasites (Monogenea) from cichlid fishes in Africa, the Levant and Madagascar. Zoosystema 31 (4): 849-898.

Paperna, I. (1963): Enterogyrus cichlidarum n. gen. n. sp., a monogenetic trematode parasitic in the intestine of fish. The Bulletin of the Research Council of Israel, 11B, 183-187.

Rawson, MV. and Rogers, WA. (1972): Seasonal abundance of ancyrocephalinean (Monogenoidea) parasites of blue gill, Lepomis macrochirus (Raf). Journal of Wildltfe Diseases 8: 255-260.

Shareef, PA. and Abidi, SMA. (2012): Incidence and histopathology of encysted progenetic metacercaria of Clinostomum complanatum (Digenea: Clinostomidae) in Channa punctatus and its development in experimental host. Asian Pacific Journal of Tropical Biomedicine vol. 2 issue 6. p. 421-426

Thatcher, V. (2006): Amazon fish parasites. Pensoft, Moscow.

Yamaguti, S. (1985): Systema helminthes of fish. Vol 1.Digentic Trematodes of the vertebrates part 1 and 2, Interscience publishers, Inc. New York.

\footnotetext{
وبائية الإصابة بالديدان المفلطحة في معدة أسماك البلطي النيلي بمحافظة أسيوط

أحمد عبل الهادى الكامل

إن الهدف من هذا البحث هو دراسة معدلات الإصابة بالدودة المفلطحة احادية العائل إنتيروجيرس سيكلبدرم في معدة أسماك البلطي النيلي، قابلية

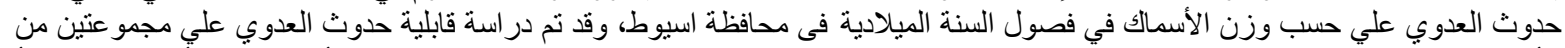

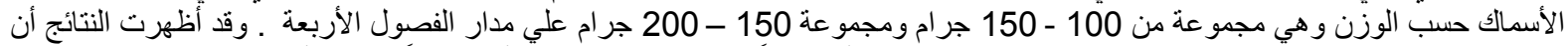

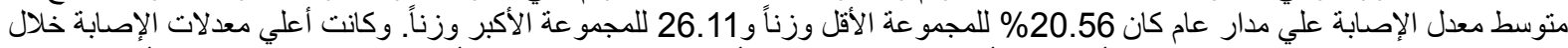

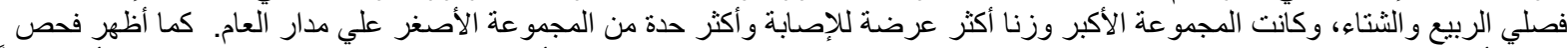

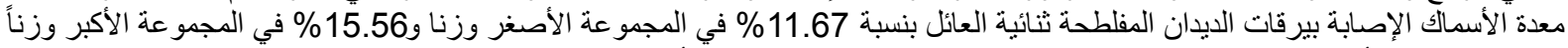

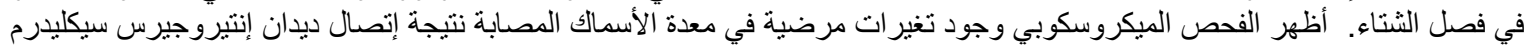

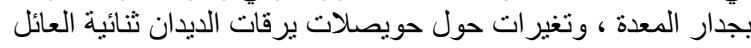

